\title{
Imported measles outbreaks prompt call for parents to vaccinate their children
}

$\mathrm{M}$

any young doctors in Canada have never seen a patient with measles, but those days may be numbered. On Mar. 10, a British Columbia religious school whose members oppose vaccination was temporarily closed because of fears that the measles virus may have infected more than 100 students. So far there are five confirmed cases. Earlier this year, there were small outbreaks in Calgary, Alberta (4) and Ottawa, Ontario (2). And in 2011, there were more than 700 cases of measles in Quebec.

All these cases in a purported measles-free country are prompting public health experts to call for more widespread vaccination.

"We're definitely urging parents to get their children vaccinated," said Sylwia Krzyszton, a spokesperson for the Public Health Agency of Canada (PHAC).

She says Canada's measles vaccination rate, based on national surveys, stands at an "estimated 95\%" - sufficient for herd immunity.

However, in Fraser East, the region harbouring BC's current measles outbreak, only $88 \%$ of two-year-olds have up-to-date measles vaccination, which is "not great," says Dr. Monika Naus, medical director, Immunization Programs and Vaccine Preventable Diseases Service of the BC Centre for Disease Control. Even more concerning to her is the province's low vaccine uptake overall: seven percent of children are completely unvaccinated. "You know you can't eliminate measles when you need 95\%."
Among the province's unvaccinated are the 450 students at Mount Cheam Christian School, the centre of this latest outbreak. The school is operated by the Reformed Congregation of North America, which is closely tied to the ultra-orthodox Netherlands Reformed Congregation in Holland. Its members reject vaccination on the grounds that immunizing their children challenges the will of God.

"The community is fully aware of measles and how it is transmitted and they have made a choice of taking nonvaccine measures," said Naus. This means self-quarantine for 21 days postexposure for everyone in a household.

More than 100 children at the school were at risk of exposure, she says, but there are relatively few confirmed cases

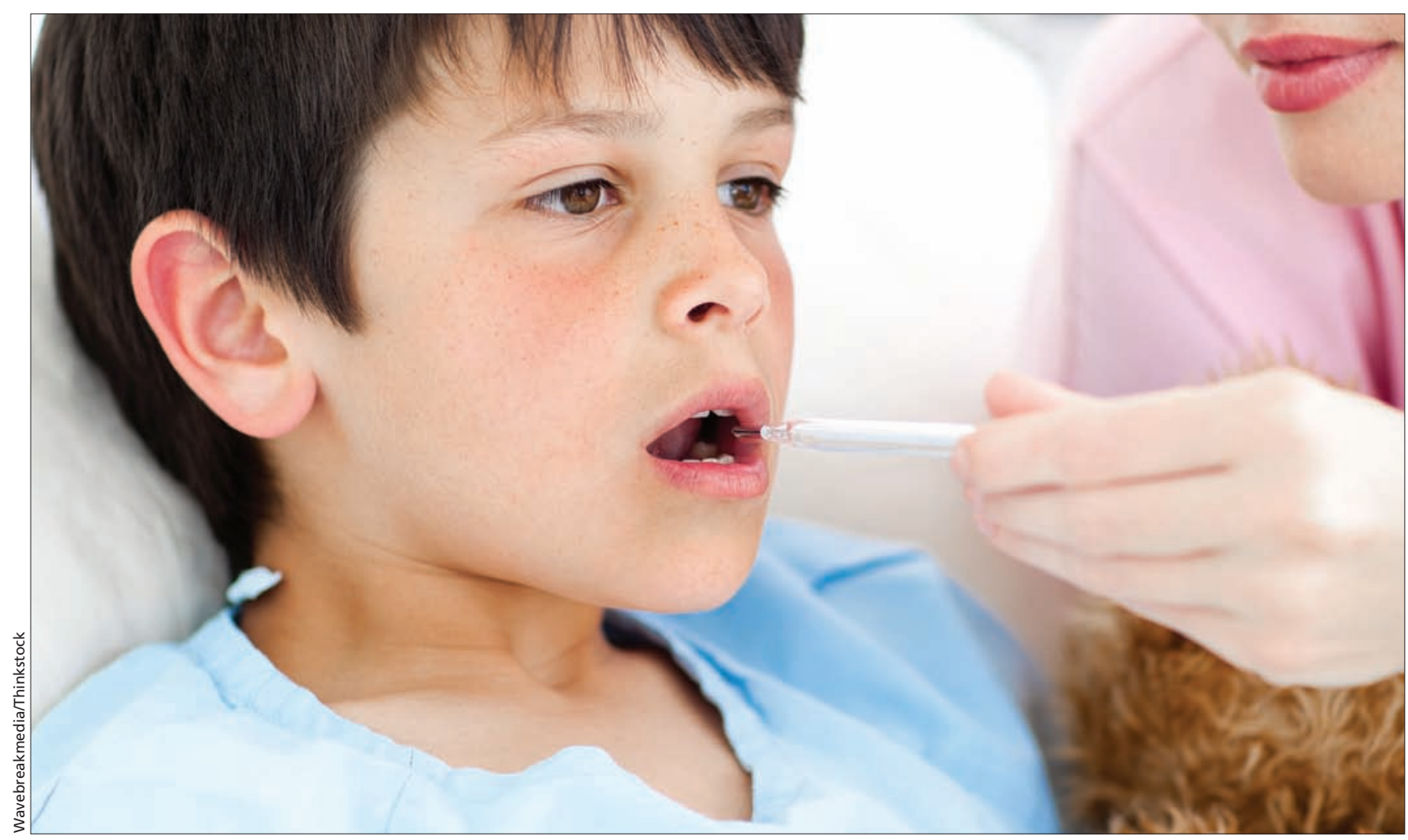

As many as 1 in 20 children with measles gets pneumonia and about 1 in 1000 develops encephalitis. For every 1000 children who get measles, 1 or 2 will die from it. 
because children are discouraged from routine testing that would bring them to hospitals and clinics. "Counting will be through self-reported symptoms," says Naus.

"A large outbreak is unfolding at present," says Naus. "For now, it's limited to this community."

Measles has an incubation period of a couple weeks, so it's too early to determine how many people will ultimately develop the disease.

\section{Imported disease}

Measles is relatively rare in Canada, says PHAC's Krzyszton, but imported cases do occur as the highly infectious disease remains endemic in many countries. "The challenge is in the 'pockets' of unimmunized that are more prone to outbreaks and the risk of importations by travellers," she stated in an email.

This is the third time in the past year that measles has been imported from the Netherlands to BC. The first two times resulted in only a few cases.

The 42 cases of measles in Southern Alberta at the Coaldale Christian School in November 2013, were also the result of a student importing the disease from the Netherlands.

Another hot spot is the Philippines. The measles cases in Ottawa involved a student who became ill the day after returning from the Philippines. Two of the three initial patients with measles in Calgary also had links to the Philippines.

PHAC is warning travellers to the Philippines to ensure their measles vaccination is up to date. In February, Toronto Public Health alerted clinicians to watch for measles because a widespread outbreak in the Philippines, which reportedly killed more than 24 children in 2013, seems to be slowly spreading to Canada.

Taiwan and the United Kingdom have also reported people returning from the Philippines with measles. The Philippines is now vaccinating about two million children in and around Manila.

The hot spots are continually changing. The serious outbreak in Quebec in 2011 was linked to cases imported from France.

"Quebec is an example of what could happen," says Naus. "We shouldn't need an outbreak in our backyard to make people [get vaccinated]."

Dr. Rosamund Lewis, associate medical officer of health in Ottawa also believes the vaccination rates need to improve and that a few factors drive the current trend toward not vaccinating.

"One is complacency. We don't see a lot of these conditions. Some people feel the risk of the vaccine may be higher than the risk of the disease. The second thing is the growth of the internet - access to all kinds of information misinformation and false information."

Exhibit A is the now retracted and debunked 1998 Lancet article that suggested a link between autism and the measles, mumps and rubella vaccine. Right now there is no evidence of that link," says Lewis.

\section{Serious disease}

Lewis hopes these latest outbreaks will serve as a reminder to the public and health care providers about the potential severity of measles. According to the US Centers for Disease Control and Prevention, as many as 1 in 20 children with measles gets pneumonia and about 1 in 1000 develops encephalitis. For every 1000 children who get measles, 1 or 2 will die from it.

Globally, measles is one of the leading causes of death among young children, according to the World Health Organization: 122000 children died as a result of measles in 2012. And it used to be much worse. Intense measles vaccination efforts netted a $78 \%$ decline in deaths between 2000 and 2012.

"But because measles is so contagious, it will eventually find every unimmunized person," says Lewis. Gordon Giddings and Barbara Sibbald CMAJ

CMAJ 2014. DOI:10.1503/cmaj.109-4759 